\title{
Interaction of polymer with clays
}

Jyotsana lal ${ }^{1}$ and Loic Auvray ${ }^{2}$

${ }^{1}$ IPNS , ANL, Argonne IL-60439, USA.

${ }^{2}$ LLB, CE-SACLAY, 91191 Gif-Sur-Yvette, FRANCE.

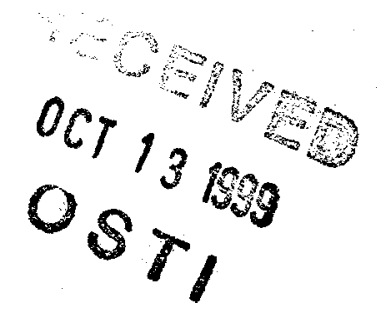

\begin{abstract}
Normally synthetic well defined monodisperse discotic laponite clays are known to form a gel phase at mass concentrations as low as a few percent in distilled water. Hydrosoluble polymer polyethylene oxide was added to this intriguing clay system, it was observed that it either prevents gelation or slows it down extremely depending on the polymer weight, concentration or the laponite concentration. Small Angle Neutron scattering (SANS) was used to study these systems because only by isotopic labelling can the structure of the adsorbed polymer layers be determined. The contrast variation technique is specifically used to determine separately the different partial structure factors of the clay and polymer. In this way the signal of the adsorbed chains is separated from the signal of the free chains.
\end{abstract}

The submitted manuscript has been created The submitted manuscript has been created by the Univertional Laboratory ("Argonne") Argonne National Laborat-109-ENG-38 with under Contract No. W-31-109-ENG. The U.S. the U.S. Department of Energy. The U.S. Government retains for itself, and others acting on its behalf, a paid-up, nonexclusive, irrevocable worldwide license in said article to reproduce, prepare derivative works, dis tribute copies to the public, and perform pubtribute copies to the public, and perly and display publicly, by or on behalf of
licly a the Government. 


\section{DISCLAIMER}

This report was prepared as an account of work sponsored by an agency of the United States Government. Neither the United States Government nor any agency thereof, nor any of their employees, make any warranty, express or implied, or assumes any legal liability or responsibility for the accuracy, completeness, or usefulness of any information, apparatus, product, or process disclosed, or represents that its use would not infringe privately owned rights. Reference herein to any specific commercial product, process, or service by trade name, trademark, manufacturer, or otherwise does not necessarily constitute or imply its endorsement, recommendation, or favoring by the United States Government or any agency thereof. The views and opinions of authors expressed herein do not necessarily state or reflect those of the United States Government or any agency thereof. 


\section{DISCLAIMER}

Portions of this document may be illegible in electronic image products. Images are produced from the best available original document. 


\section{Introduction}

Complexes formed by clay -polymer have tremendous importance in agriculture and industry. In order to gain further understanding of such complicated systems we decided to study the polymer interactions with a model system of artificial clays. Normally synthetic well defined monodisperse laponite clays is made of microcrystalline magnesium silicate, disk or coin like platelets of diameter $\sigma \cong 250 \AA$ and thickness $h \cong 9.2$ $\AA$. The platelets carry a negative charge, due to isomorphous substitution of fraction of $\mathrm{Mg}^{2+}$ by $\mathrm{Li}^{+}$ions; resulting in a unit cell of $-0.7 \mathrm{e}$ charge. These elementary charges (roughly -700e) are uniformly distributed over the disks, while a smaller positive charge, originating from broken bonds, is concentrated along the rim $(1,2)$. The overall negative charge of the platelets is compensated by $\mathrm{Na}^{+}$counterions which form electric double layers around the laponite disks suspended in water.

Discotic Laponites are known to form a gel phase at mass concentrations as low as a few percent in distilled water (2). Accounting for gel like behavior at low concentration of compact clay particles poses a theoretical challenge. One of the reasons for the existence of strong interactions in these systems is attributed to attraction due to difference in charge between edge and surface (3). Another explanation, for gel formation is linked to strong electrostatic repulsion between overlapping double layers coupled to steric hindrance between anisotopic charged coin-like particles (4). Monte Carlo simulations (2) were performed on the laponite suspensions which are more amenable to a statistical description than natural clays. The structure of gels from the simulations was compatible with "house of cards" three- dimensional structure (3). However, no experimental evidence exists of such structure. The microstructure of these gels has been recently studied by neutron, $x$-ray and light scattering studies $(5,6)$ and seem to be hetergeneous and exhibits fractal behavior. Another, important aspect is that at low particle concentration the gel is optically anisotropic and at higher concentration a nematic texture is observed (7). 
We added hydrosoluble polymers to this intriguing clay system, we observed that it either prevents gelation or slows it down extremely depending on the polymer weight, concentration or the laponite concentration. Polymer adsorption holds the key to an understanding of formation and properties of clay-polymer mixtures. Adsorption of neutral polymer chains at ideal surfaces has been studied for the last decades and is now quite well understood (8). In order to understand more profoundly clay-polymer mixtures we investigated their structure by Small Angle Neutron scattering (SANS).

There has been some recent theoretical interest in Polymer-Clay composites as well (9). This theory models the phase behavior for a mixture of polymers and solid, thin discs. Their theory takes into account the possible nematic ordering of the discs within the polymer matrix. In this model the electrostatic interactions are not taken explicitly into account but which normally exist in clay systems.

In this paper, we briefly report the Small Angle Neutron scattering (SANS) study of mixed systems of polymer and laponite clays using contrast variation techniques.

\section{Experimental Methods}

Clay - Laponite XLG, a synthetic microcrystalline swelling clay of a hectorite type was provided as a white powder by Laporte Industries Ltd. (1). Its idealised molecular formula is as follows

$$
\mathrm{Na}_{0.7}^{+}\left[\left(\mathrm{Si}_{8} \mathrm{Mg}_{5.5} \mathrm{Li}_{0.3}\right) \mathrm{O}_{20}(\mathrm{OH})_{4}\right]^{0.7-}
$$

Polymer- The polymer Polyethylene oxide of $\mathrm{M}_{\mathrm{w}}=58900\left(\mathrm{M}_{\mathrm{w}} / \mathrm{M}_{\mathrm{n}}=1.06\right)$ and $M_{w}=100,000\left(M_{w} / M_{n}=1.04\right), M_{w}=334,500\left(M_{w} / M_{n}=1.14\right)$ were purchased from Polymer Source and $\mathrm{M}_{\mathrm{w}}=1.14 \times 10^{6}\left(\mathrm{M}_{\mathrm{w}} / \mathrm{M}_{\mathrm{n}}=1.13\right)$ from Polymer Standards Service. Another similar series of polymer Polyethylene oxide of $M_{w}=563000\left(M_{w} / M_{n}=1.05\right)$ and 
$\mathrm{M}_{\mathrm{w}}=105,000\left(\mathrm{M}_{\mathrm{w}} / \mathrm{M}_{\mathrm{n}}=1.06\right)$ and $\mathrm{M}_{\mathrm{w}}=8.47 \times 10^{5}\left(\mathrm{M}_{\mathrm{w}} / \mathrm{M}_{\mathrm{n}}=1.1\right)$ was a gift from MSD Argonne; which were used in some initial experiments.

Solvent -The solvent Deuterium oxide $\left(\mathrm{D}_{2} \mathrm{O}\right)$ was purchased from Aldrich and the hydrogenated water was Millipore filtered. The volume fraction of $\mathrm{D}_{2} \mathrm{O}$ in the $\mathrm{H}-\mathrm{D}$ mixture was $17 \%, 66 \%$ and $100 \%$.

Small Angle Neutron scattering (SANS)- The neutron scattering experiments were done at Laboratoire Leon Brillouin (ORPHEE reactor at Saclay) on the the spectrometer PACE equipped with an isotropic multidetector. The wavelength $\lambda$ used was $15 \AA$ (sample-detector distance was $4.58 \mathrm{~m}$ ) and at $6 \AA$ (sample-detector distance was $3.0 \mathrm{~m}$ ). The two configurations used covered a q range from 0.0025 to $0.11 \AA^{-1}$. The data was appropriately treated for background, etc. and put on an absolute scale. A part of the data was taken at the Intense Pulsed Neutron Source at Argonne on the SAD instrument at Argonne which covers a $q$ range from 0.005 to $0.35 \AA^{-1}$.

\section{Results and Discussion}

Most of the scattering has been performed in the intermediate wave vector regime, $\mathrm{qR} \sim 1$ i.e. the Porod's regime. In this range of scattering vectors the problem of interaction between particles is less crucial and we are sensitive to interfacial structures. SANS can be use directly to study the structure of a polymer layer near an interface (10) such as local structure of polymer adsorbed on colloidal grains or porous media. This viewpoint has been extensively developed in reference 10 . In general the scattering intensity $\mathrm{I}(\mathrm{q})$ depends not only on the average concentration profile perpendicular to the interface $I_{\text {PROFLE }}$ but also on the concentration correlations parallel to the layer $I_{\text {CORRELATION }}$. $\mathrm{I}_{\text {CORRELATION }}$ include correlation of the bulk chains as well.

$$
I(q)=I_{\text {PROFILE }}+I_{\text {CORRELATION }}
$$

If $n_{G}, n_{S}$ and $n_{p}$ are respectively, the scattering length densities of the solid (laponite- 
denote by $\mathrm{G}$ ), the solvent and the polymer, then

$$
\begin{aligned}
& \mathrm{I}_{\text {CORRELATION }}=\left(\mathrm{n}_{\mathrm{p}}-\mathrm{n}_{\mathrm{S}}\right)^{2} \mathrm{~S}_{\mathrm{H}}(\mathrm{q}) \\
& \mathrm{I}_{\text {PROFILE }}=2 \pi \mathrm{S}_{\mathrm{P}} N \mathrm{q}^{-2}|\mathrm{a}(\mathrm{q})|^{2}
\end{aligned}
$$

where, $a(q)=\int_{-\infty}^{\infty} n(z) e^{i q z} d z$, is the fourier transform of the profile of $n(z)$. The profile $n(z)$ around the laponite particle is even (Figure 1) hence, $a(q)=2 \int_{0}^{\infty} n(z) \cos$ (qz) dz. If $\mathrm{D}$ is the thickness of the laponite particle,

$$
\begin{aligned}
& Z<D / 2, n(z)=n_{G} \text { (laponite) } \\
& \text { and for } Z>D / 2, \quad n(z)=n_{P} \phi_{P}(z)+n_{S}\left(1-\phi_{P}(z)\right) .
\end{aligned}
$$

$\phi_{\mathrm{P}}(\mathrm{z})$ is the average volume fraction of the polymer a distance $\mathrm{z}$ from the wall.

Hence $\mathrm{a}(\mathrm{q})=2\left[\left(\mathrm{n}_{\mathrm{G}}-\mathrm{n}_{\mathrm{S}}\right) \int_{0}^{D / 2} \cos (\mathrm{qz}) \mathrm{dz}+\left(\mathrm{n}_{\mathrm{P}}-\mathrm{n}_{\mathrm{S}}\right) \int_{D / 2}^{\infty} \phi_{\mathrm{P}}(\mathrm{z}) \cos (\mathrm{qz}) \mathrm{dz}\right]$.

From the total scattered intensity I(q) using contrast variation experiments we can separate three partial structure factors related to solid-solid $S_{\mathrm{GG}}(\mathrm{q})$, solid-polymer $\mathrm{S}_{\mathrm{PG}}(\mathrm{q})$, and polymer-polymer $S_{\mathrm{PP}}(\mathrm{q})$, correlations.

$$
I(q)=\left(n_{G}-n_{S}\right)^{2} S_{G G}(q)+\left(n_{P}-n_{S}\right)^{2} S_{P P}(q)+2\left(n_{G}-n_{S}\right)\left(n_{p}-n_{S}\right) S_{P G}(q)
$$

Here $n_{I}$ is the neutron scattering length density and $n_{I}-n_{J}$ is the contrast factor. $S_{i j}(q)$, are the partial structure factors. A mixture of hydogenated and deuterated solvent enables us to vary $n_{S}$ at constant $n_{G}$ and $n_{p}$. At $17 \%$ of $D_{2} O$ we match the polymer and observe $\mathrm{S}_{\mathrm{GG}}(\mathrm{q})$. At $66 \% \mathrm{D}_{2} \mathrm{O}$ we match the contrast between the solid laponite and solvent and we observe $S_{\mathrm{pp}}(\mathrm{q})$. 
In the range of small scattering vectors, $\mathrm{qh}<1$, where $\mathrm{h}$ is the thickness of the interfacial layer (but $\mathrm{q}$ in still the Porod's regime), the scattering is only sensitive to the global characteristic of the layer structure:

-interfacial amount of polymer $\gamma=\int_{-\infty}^{\infty} \mathrm{dz} \phi(\mathrm{z})$ and it expressed in $\AA$. If $\gamma(\AA)$ is known we can deduce the quantity of polymer adsorbed $\Gamma\left(\mathrm{mg} / \mathrm{m}^{2}\right)=\rho \gamma$ where $\rho$ is density of polymer.

From the above expression ( 3 and 4 ), the partial structure factors can be re-written in terms of $\gamma$, the specific area of one side of laponite $=400 \mathrm{~m}^{2} / \mathrm{g}$ hence $S_{1} / V=\left(400 \mathrm{~m}^{2} / \mathrm{g} \cdot C_{L}\right.$ $\left.\left(\mathrm{g} / \mathrm{cm}^{3}\right)\right)$; here $\mathrm{c}$ is concentration of laponite; $\phi_{\mathrm{L}}=\phi_{\mathrm{G}}=\mathrm{C}_{\mathrm{L}} / \rho_{\mathrm{L}}$ where is $\rho_{\mathrm{L}}=2.65 \mathrm{~g} / \mathrm{cm}^{3}$ density of laponite and similarly, $\phi_{P}=C_{P} / \rho_{P}$ where is $\rho_{P}=1.13 \mathrm{~g} / \mathrm{cm}^{3}$ density of polymer. The thickness of laponite $\mathrm{D}=9.2 \mathrm{~A}$. Thus, in the limit $\mathrm{q} \rightarrow 0$

$$
\begin{aligned}
& \mathrm{q}^{2} S_{\mathrm{GG}}(\mathrm{q})=2 \pi \mathrm{S}_{1} / V D^{2}=2 \pi \phi_{\mathrm{L}} \mathrm{D} \\
& \mathrm{q}^{2} \mathrm{~S}_{\mathrm{PP}}(\mathrm{q})=2 \pi \mathrm{S}_{1} / \mathrm{V} \gamma^{2}=2 \pi \phi_{\mathrm{P}} \gamma \\
& \mathrm{q}^{2} \mathrm{~S}_{\mathrm{PG}}(\mathrm{q})=2 \pi \mathrm{S}_{1} / \mathrm{VD} \gamma=2 \pi \phi_{\mathrm{L}} \gamma=2 \pi \phi_{\mathrm{P}} \mathrm{D}
\end{aligned}
$$

At large angles,

$$
\mathrm{q}^{2} S_{\mathrm{pP}}(\mathrm{q})=2 \pi \mathrm{S}_{1} / \mathrm{V} \gamma^{2}\left(1-\mathrm{h}^{2} \mathrm{q}^{2} / 12\right)+\mathrm{q}^{2} S_{\mathrm{pp}}(\mathrm{q}=0)
$$

Here $\mathrm{q}^{2} S_{\mathrm{pp}}(\mathrm{q}=0)$ contains the contribution of bulk free chains and is positive. Similarly, the other interfacial polymer structure factor can be written as

$$
\mathrm{q}^{2} S_{\mathrm{PG}}(\mathrm{q})=2 \pi \mathrm{S}_{1} / N D \gamma\left(1-\mathrm{h}^{2} \mathrm{q}^{2} / 12\right)=2 \pi \phi_{\mathrm{L}} \gamma\left(1-\mathrm{h}^{2} \mathrm{q}^{2} / 12\right)
$$


In Figure 2, is shown the scattering, from bare laponite, free polymer and laponite and polymer mixture in heavy water in non-matched conditions. The scattering from bare laponite shows an asymptotic slope of -2 , which is a sign of scattering from very thin layers $(\sim 10 \AA)$. The scattering from free polymer chains show an asymptotic slope of -1.58. In addition, we observe that the scattering by mixture of laponite and polymer is not just the addtion of scattering curves of bare laponite and free polymer. This means that there is some interaction between the polymer and the laponite. It seems that the polymer decorates the surface of laponite with a better contrast as its scattering curve has a shape similar to that of bare laponite.

At this stage, to learn more about the system we need to go to contrast matching conditions. In Figure 3, we show the scattering from laponite in $66 \% \mathrm{D}_{2} \mathrm{O}$. At $66 \% \mathrm{D}_{2} \mathrm{O}$ we match the contrast between the solid laponite and solvent and we observe an almost flat scattering signal. If add $1 \%$ polymer to the above laponite solution we observe the signal from just the polymer chains i.e. $S_{\mathrm{PP}}(\mathrm{q})$. Further, a mixture of hydogenated and deuterated solvent enables us to measure the other polymer partial structure factor $S_{\mathrm{PG}}(\mathrm{q})$ for various polymer lengths and concentration and laponite concentration.

The semi- $\log$ representation of $\mathrm{q}^{2} \mathrm{~S}_{\mathrm{PP}}(\mathrm{q})$ as function of $\mathrm{q}^{2}$ are shown in Figure 4 for $2 \%$ laponite and $100 \mathrm{~K}$ POE chains at concentration of $1 \% 2 \%$ and $3 \%$ : the initial slope at small angles give the interfacial thickness $h$ and the intercept gives the value of $\gamma_{\mathrm{A}}$. The value of the intercept at limit $\mathrm{q} \rightarrow 0$ or $\gamma_{\mathrm{A}}$ remains virtually unchanged as we vary the concentration of the polymer chains. Even at $1 \%$ of polymer chains the adsorption is already saturated. As the concentration of polymer chains increases further, the intensity increases as large $\mathrm{q}$, with bigger contribution from the second term in equation 8 due to free chains. $S_{P P}(q)$ has contributions from both adsorbed and free chains, so signal at higher concentrations of polymer, i.e. at large $q$ values, gets swamped by that of free chains in solution. In order to observe signal from just adsorbed chains it better to consider the second partial polymer structure factor $S_{P G}(q)$. 
In case of laponite we are insensitive to the details of the shape profile because for a very singular concentration profile as one expects from adsorbed polymer, the fourier transform is dominated by its low q contribution (11). Inspite of this, it is important to measure $\mathrm{S}_{\mathrm{PG}}(\mathrm{q})$ by contrast variation because it measures chains which are correlated to the laponite particles and the signal is independent from that of free chains. Thus we can deduce the amount of chains that are adsorbed from the bulk free chains. $S_{\mathrm{PP}}(q)$ has contributions from both adsorbed and free chains.

In Figure 5 is plotted $\mathrm{q}^{2} \mathrm{~S}_{\mathrm{PG}}(\mathrm{q})$ as function of $\mathrm{q}^{2}$ for $2 \%$ laponite and 100K POE chains at concentration of $1 \% 2 \%$ and $3 \%$ : the initial slope at small angles give the interfacial thickness $h$ and the intercept gives the value of $\gamma_{A}$. Again $\gamma_{A}$ measured are virtually unchanged within experimental error for all the measured polymer concentrations.

As noted above $S_{P G}(q)$ can be used to deduce $\gamma_{\mathrm{A}}$ for the adsorbed chains from the data, whereas we can calculate a $\gamma_{\mathrm{P}}\left[\gamma_{\mathrm{P}}=\phi_{\mathrm{P}} \mathrm{D} / \phi_{\mathrm{L}}\right.$ or $\left.\gamma_{\mathrm{P}}=\phi_{\mathrm{P}} /\left(\mathrm{S}_{1} / \mathrm{V}\right)\right]$ if it assumed that all chains are adsorbed. Thus we can deduce the percentage of adsorbed and free chains for various concentrations of laponite and polymer, polymer molecular weight values are listed in Table 1 below.

The number of free chains increases as opposed to adsorbed chains, with increase in polymer concentration at fixed laponite concentration. Within experimental error, $\Gamma\left(\mathrm{mg} / \mathrm{m}^{2}\right)$ seems to already saturate at the lowest polymer concentration measured.

\section{Conclusions}

We are not sensitive to the shape of the polymer concentration profile $\phi_{\mathrm{P}}(\mathrm{z})$. The interfacial polymer partial structure factors vary as: $S_{\mathrm{pP}}(\mathrm{q}) \sim \gamma^{2} \mathrm{q}^{2}$ and $\mathrm{S}_{\mathrm{PP}}(\mathrm{q}) \sim \gamma \mathrm{q}^{2}$. The adsorbed layers are thin from point of view of mass distribution. We have been clearly able to separate the contribution from bulk and adsorbed polymer chains using the 
method of contrast variation. It seems if we use small molecular weight polymer chains we can keep the laponite in a sol state at concentration higher than $2 \%$ and prevent or slow down the process of gelling.

The above method of contrast variation to study adsorption of polymer has not just been used to study solid colloidal particles but also has been used in case of weaker and softer aggregates, in particular micelles, microemulsion droplets (12) and lipid membranes (13). 


\section{References}

(1) Laporte Inorganics-Laponite-The Technical Directory.

(2) Dijkstra, M., Hansen, J.P. \& Madden, P.A. (1995). Physical Review Letters, 75(11), 2236-2239.

(3) van Olphen, H. (1977). An introduction to Clay Colloid Chemistry, Wiley, New York.

(4) Norrish, K. (1954). Discussions of Faraday Society, 18, 120-134.

(5) Pignon, F., Piau, J.-M. \& Magnin, A. (1996). Physical Review Letters, 76(25), 4857 -4860 .

(6) Pignon, F., Magnin, A., Piau, J-M., Cabane, B. , Lindner, P. , \& Diat , O. (1997). Physical Review E, 56, 3281-3289.

(7) Gabriel, J.-C. P., Sanchez, C. \& Davidson, P. (1996). J. Phys. Chem., 100 (11), 139.

(8) Fleer, G.J. , Cohen Stuart, M.A., Scheutjens, J.M.H.M., Cosgrove, T. \&Vincent, B. (1993). Polymer at Interfaces, Chapman \& Hall, London.

(9) Lyatskays, Y. \& Balazs, A. C. (1998). Macromolecules, 31, 6676-6680.

(10) Auvray, L. \& Auroy, P. (1991). Neutron, X-Ray and Light Scattering, edited by P. Lindner \& T. Zemb, pp.199-221, North-Holland, Elsevier Science Publishers.

(11) Auvray, L. \& de Gennes, P.G. (1986). Europhysics Letters, 2(8), 647-650.

(12) Lal, J. \& Auvray, L. (1994). J. Phys II, 4, 2119-2125.

(13) Joannic, R., Auvray, L. \&Lasic, D.D. (1997). Phys. Rev. Lett., 78, 3402-3405. 


\section{Figures}

Figure 1. Left: Geometry of the polymer coated laponite particle.

Right: Profile of the scattering length density.

Figure 2. Scattering from bare laponite $\mathrm{XLG} 1 \%$, polymer $1 \%(\mathrm{Mw}=900 \mathrm{~K})$ and a mixture laponite XLG $1 \%$ and $1 \%$ polymer in $\mathrm{D}_{2} \mathrm{O}$.

Figure 3. The scattering from laponite $\mathrm{XLG} 1 \%$ in $66 \% \mathrm{D}_{2} \mathrm{O}$ and laponite $\mathrm{XLG} 1 \%$ plus POE $1 \% 56.3 \mathrm{~K}$ in $66 \% \mathrm{D}_{2} \mathrm{O}$.

Figure 4. Semi-log representation of $\mathrm{q}^{2} \mathrm{~S}_{\mathrm{PP}}(\mathrm{q})$ as function of $\mathrm{q}^{2}$ are shown for $2 \%$ laponite XLG and 100K POE chains at concentration of $1 \% 2 \%$ and $3 \%$ (units on y axis$\left.* 10^{-4} \mathrm{~cm}\right)$.

Figure 5. Semi-log representation of $\mathrm{q}^{2} \mathrm{~S}_{\mathrm{PG}}(\mathrm{q})$ as function of $\mathrm{q}^{2}$ are shown for $2 \%$ laponite XLG and 100K POE chains at concentration of $1 \% 2 \%$ and $3 \%$ (units on y axis$\left.* 10^{-4} \mathrm{~cm}\right)$. 
Table I

\begin{tabular}{|c|c|c|c|c|c|c|c|}
\hline$C_{L}\left(\mathrm{~g} / \mathrm{cm}^{3}\right)$ & $\mathrm{C}_{\mathrm{P}}\left(\mathrm{g} / \mathrm{cm}^{3}\right)$ & $\mathrm{Mw}$ & \multicolumn{4}{|c|}{ (calculated) } & $\Gamma\left(\mathrm{mg} / \mathrm{m}^{2}\right)$ \\
\hline 0.01 & 0.02 & $102 \mathrm{~K}$ & 31.6 & 7.70 & 44 & 17.5 & 0.871 \\
\hline 0.01 & 0.01 & $847 \mathrm{~K}$ & 28.4 & 7.71 & 22 & 35.1 & 0.871 \\
\hline 0.01 & 0.02 & $847 \mathrm{~K}$ & 22.5 & 7.85 & 44 & 17.8 & 0.887 \\
\hline 0.02 & 0.01 & $100 \mathrm{~K}$ & 22.1 & 6.71 & 11 & 61.0 & 0.758 \\
\hline 0.02 & 0.02 & $100 \mathrm{~K}$ & 27.5 & 6.18 & 22 & 28.0 & 0.698 \\
\hline 0.02 & 0.03 & $100 \mathrm{~K}$ & 23.8 & 6.08 & 33 & 18.4 & 0.687 \\
\hline 0.02 & 0.01 & $1.4 \mathrm{M}$ & 20.8 & 5.56 & 11 & 50.5 & 0.628 \\
\hline 0.02 & 0.02 & $1.4 \mathrm{M}$ & 25.0 & 5.24 & 22 & 23.8 & 0.592 \\
\hline
\end{tabular}




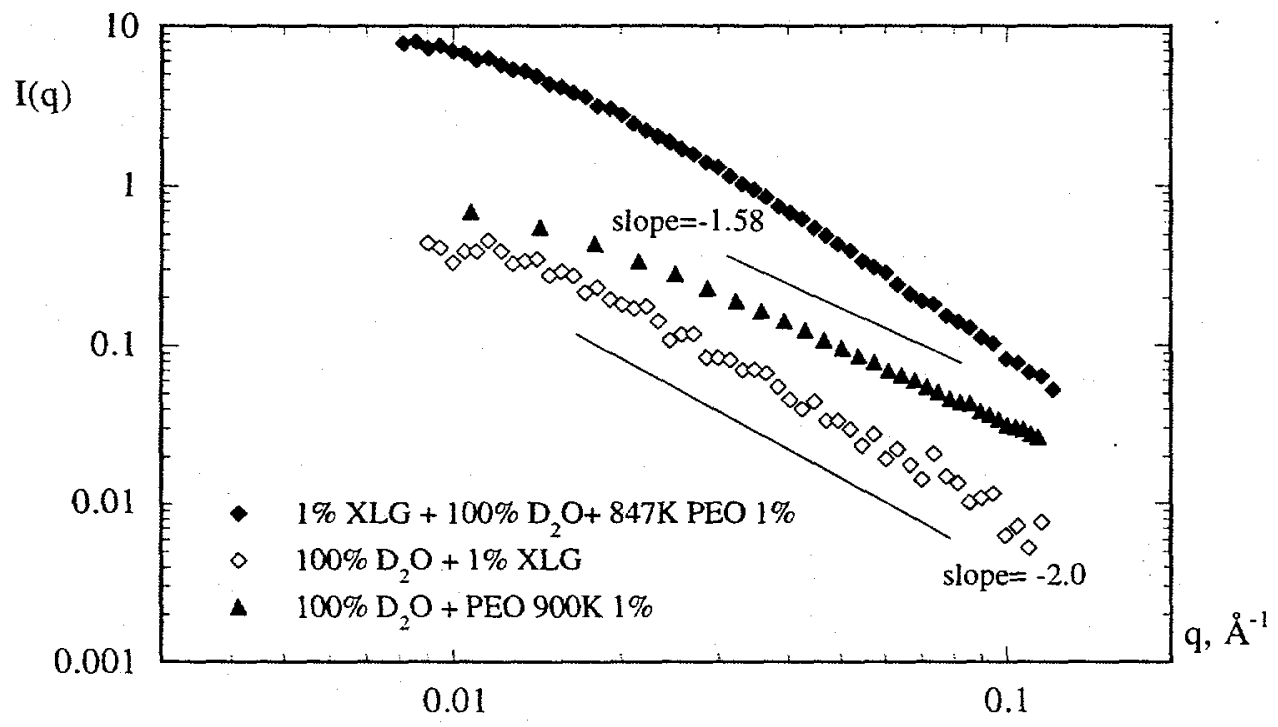




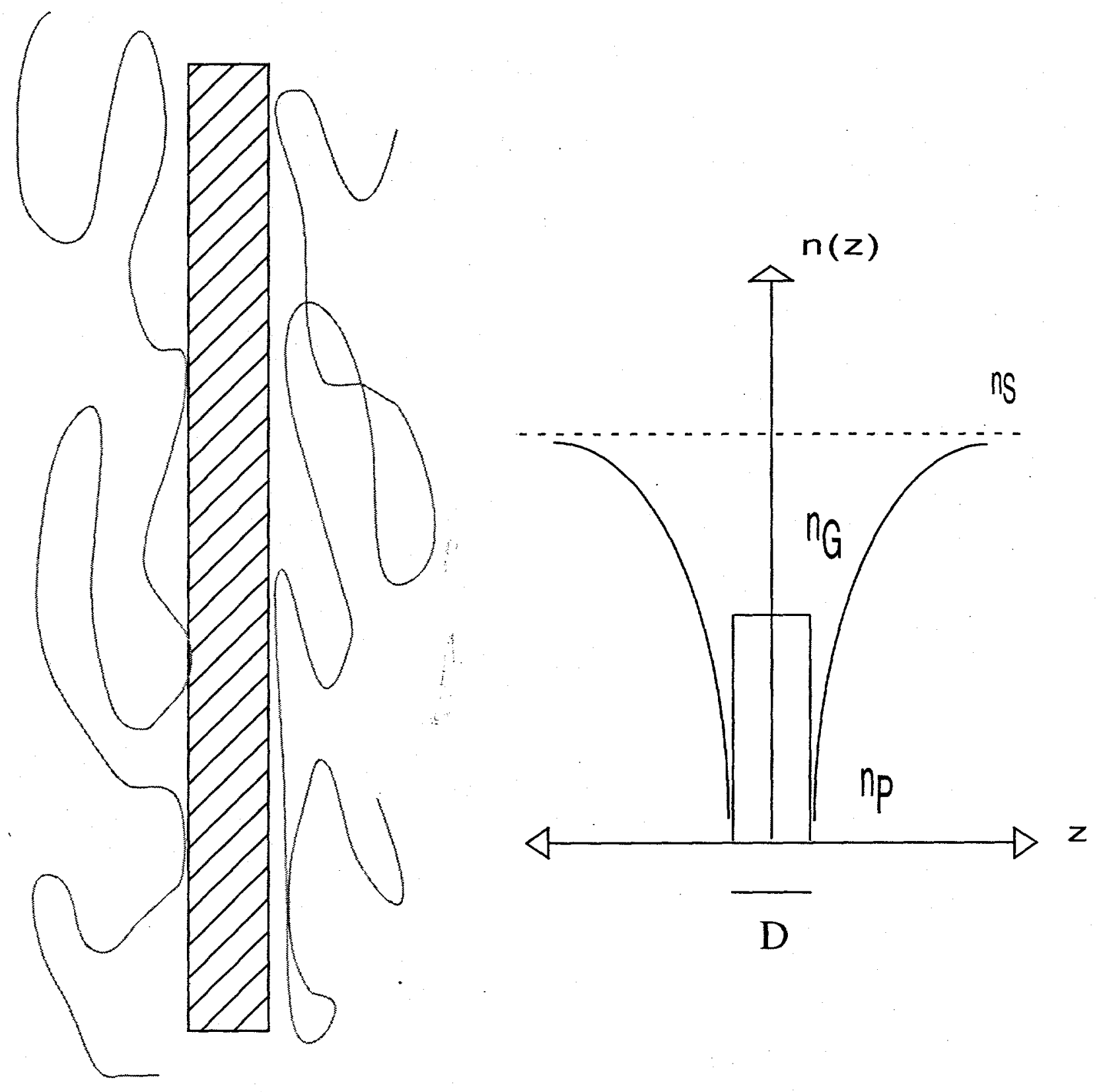




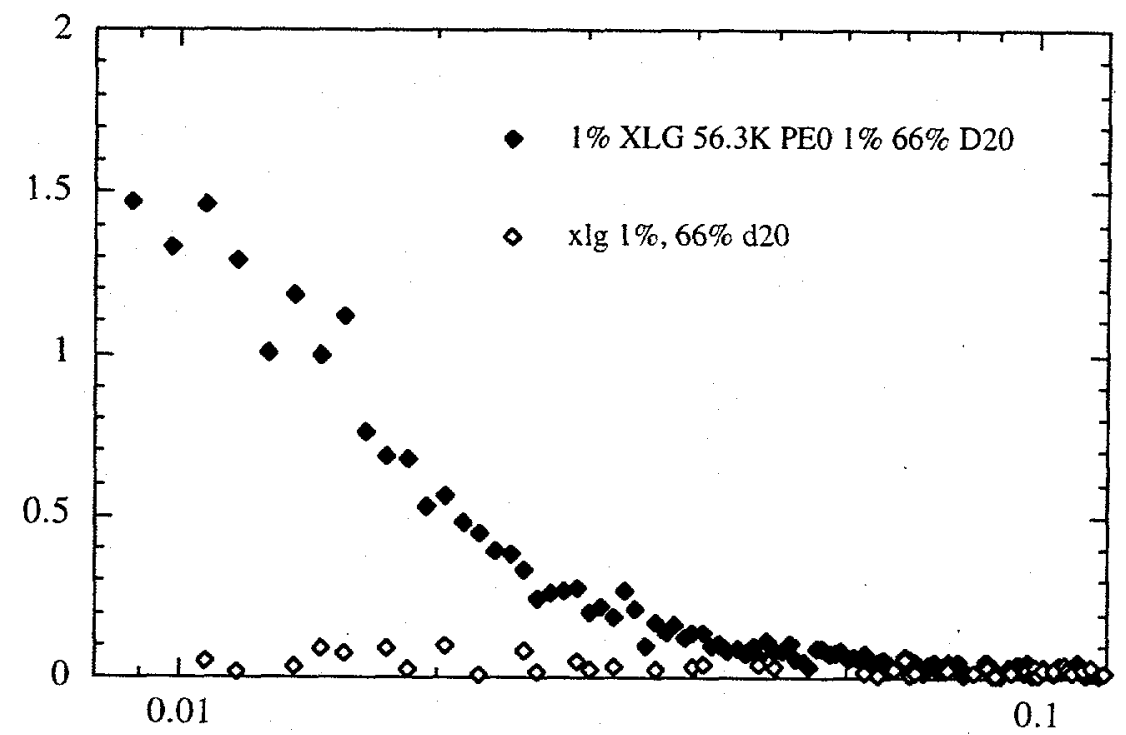




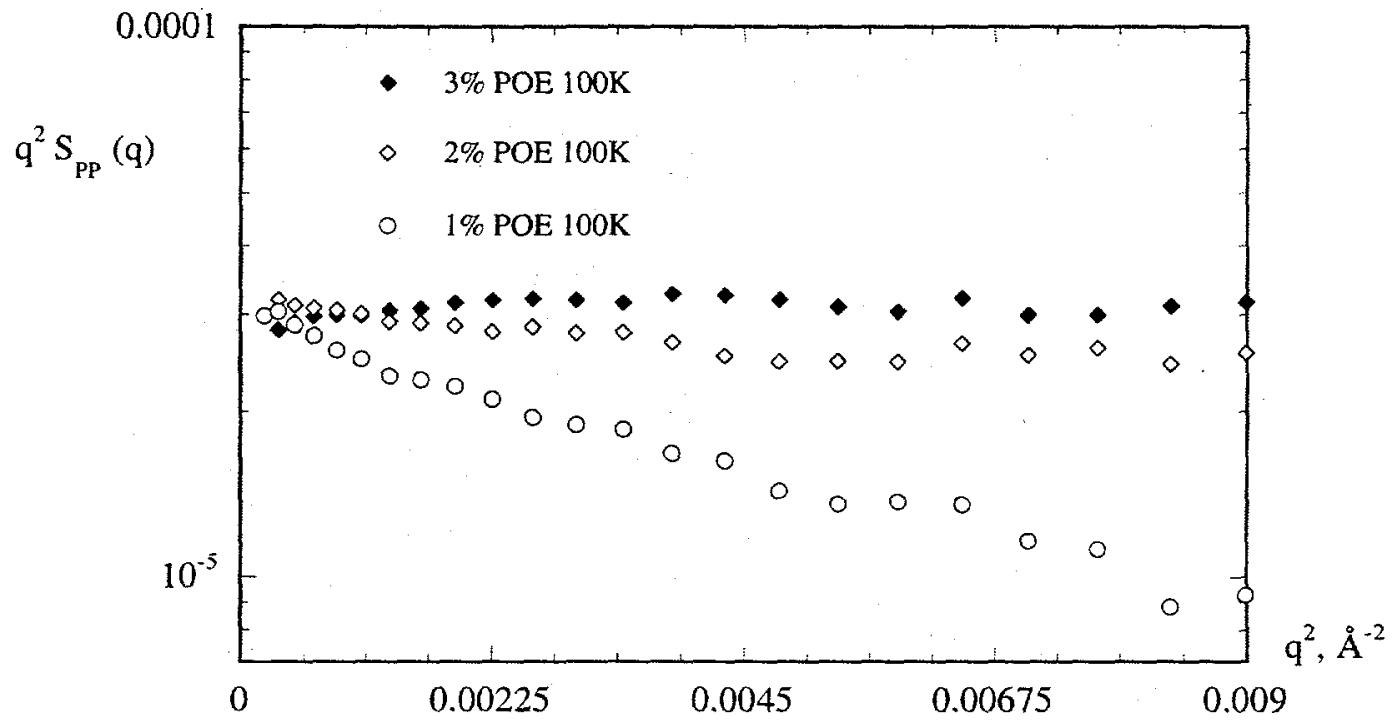




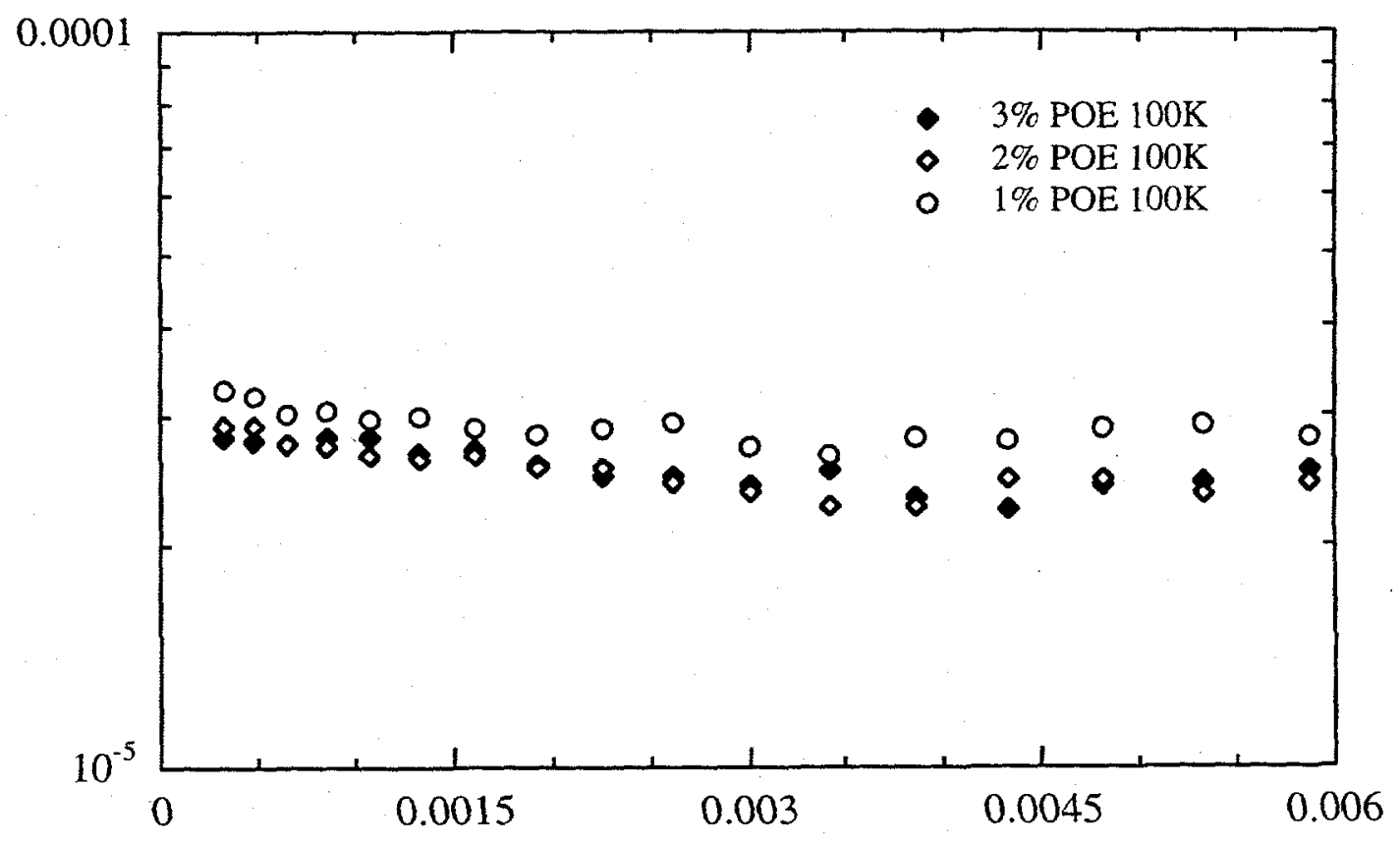

